\title{
Reciclagem e a Engenharia de Superfícies
}

Vanessa de Freitas Cunha Lins ${ }^{1}$

\author{
${ }^{1}$ Subeditora de Superfícies \\ Laboratório de Corrosão e Engenharia de Superfície, Departamento de Engenharia Química, Universidade Federal de \\ Minas Gerais, Av. Antonio Carlos, n. 6627, CEP: 31270901, Belo Horizonte, MG, Brasil. \\ e-mail: vlins@deq.ufmg.br
}

\section{INTRODUÇÃO}

A reciclagem é a ação de se aplicar um processamento a um dado material transformando-o em um novo produto ou matéria prima de forma a reutilizá-lo. O destino de resíduos sólidos urbanos tem sido tema de inúmeras pesquisas recentes [1] e a incineração de resíduos ainda é um processo eficiente em termos de aproveitamento energético. Mas nos últimos anos, tem havido um esforço em se pesquisar novas aplicações para resíduos sólidos urbanos e, neste número 4 do volume 24 da revista Matéria, temos exemplos destas pesquisas como a produção de cerâmica vítrea com vidro reciclado [2] e a adição de resíduo de vidro em massa de cerâmica de alvenaria [3]. Nesta edição, é descrito o emprego de cenosferas, sub-produto da combustão do carvão, na substituição parcial à areia para a produção de materiais cimentícios de baixo peso [4]. A presente número da Matéria apresenta ainda o estudo da viabilidade econômica de mantas térmicas produzidas a partir de resíduos de asfalto para revestimento em telhados [5] e análises de dosagens de concreto asfáltico utilizando resíduos da construção e demolição de obras [6].

O grupo de pesquisa do Laboratório de Corrosão e Engenharia de Superfícies da UFMG vem desenvolvendo pesquisas para reciclagem de garrafas de poli (tereftalato de etileno) -PET pós consumo para uso como recobrimento em aços carbono com propriedades de resistência à corrosão e ao desgaste [7]. A pesquisa para desenvolver novas aplicações para as garrafas de PET pós-consumo se iniciou a partir de 1997, quando o percentual de PET reciclado era em torno de 13\% de acordo com a Associação brasileira da Indústria do PET e, atualmente, segundo a Revista Exame 57,1\% do PET é reciclado. E uma pesquisa que tem alcançado repercussão acadêmica, tecnológica e na sociedade foi a utilização de lignina como filtro solar em asfaltos. Foi publicado um artigo apresentando as vantagens da adição de lignina ao ligante asfáltico, abordando a resistência ao envelhecimento, a estabilidade térmica e o estudo reológico [8]. Foi desenvolvido um novo produto: asfalto modificado com lignina. A pesquisa adquiriu maior importância tecnológica com o início da produção de lignina em escala industrial no Brasil a partir de 2019. Os ligantes modificados com lignina apresentaram valores de penetração mais baixos do que o ligante convencional, resistindo mais ao risco e deformando menos. A lignina melhorou significativamente a resistência do asfalto ao trincamento térmico a temperaturas até $-12{ }^{\circ} \mathrm{C}$. Neste editorial, serão avaliadas as propriedades mecânicas das misturas asfálticas com ligante modificado com lignina por meio de ensaio Marshall.

\section{METODOLOGIA}

Foi utilizado o cimento asfáltico de petróleo, CAP50/70, fornecido pela Refinaria Gabriel Passos (REGAP). A lignina foi fornecida pela empresa Suzano Papel e Celulose situada na cidade de Suzano SP. As propriedades da lignina utilizada são apresentadas na Tabela 1. Foram feitas adições em massa de $1 \%, 4 \%$ e $6 \%$ de lignina ao ligante asfáltico. Para a confecção dos corpos de prova de concreto asfáltico, e posterior determinação do teor ótimo de ligante a ser adicionado, o ligante asfáltico foi aquecido a 140 ${ }^{\circ} \mathrm{C}$, já os agregados foram aquecidos a $150{ }^{\circ} \mathrm{C}$. Atingidas as temperaturas, o ligante foi misturado ao agregado por 20 minutos e, em seguida, colocado no molde de aço A compactação dos corpos de prova foi feita com energia de 75 golpes por face [9]. 
Tabela 1: Parâmetros da Lignina

\begin{tabular}{lcc}
\hline \multicolumn{1}{c}{ Parâmetros } & Resultados & Unidade \\
\hline Massa Molecular Médio Número (Mn) & $2260 \pm 32$ & $\mathrm{G} / \mathrm{mol}$ \\
Massa Molecular Médio (Mw) & $3378 \pm 79$ & $\mathrm{~g} / \mathrm{mol}$ \\
$\mathrm{Mw} / \mathrm{Mn}$ & 1,49469 & \\
Teor de cinzas em $800^{\circ} \mathrm{C}, 12 \mathrm{~h}$ & 3,3 & $\%$ \\
$\mathrm{pH}$ & 3,5 & \\
Teor de umidade & 3,8 & $\%$ \\
\hline
\end{tabular}

Através do ensaio Marshall, determina-se a estabilidade, que é a resistência máxima a compressão radial, a deformação total apresentada pelo corpo de prova desde a aplicação da carga inicial nula, até a aplicação da carga máxima, de misturas betuminosas usinadas a quente [10]. O ensaio consiste da aplicação de uma carga de compressão sobre o corpo de prova cilíndrico regular, denominado corpo de prova Marshall, de $100 \mathrm{~mm}$ de diâmetro e 63,5 mm de altura. Essa carga é aplicada no corpo de prova por meio de cabeçotes curvos padronizados. A temperatura do ensaio é de $60{ }^{\circ} \mathrm{C}$ e a taxa de carregamento de $5 \mathrm{~cm} /$ minuto. Em geral, a parte superior da prensa é fixa e o prato inferior se desloca para cima conforme a taxa citada. Devido à resistência do material, é necessária uma força crescente para manter o prato inferior movendo-se na taxa especificada. Esta força cresce até determinado ponto em que ocorre uma perda de estabilidade do material, causada por deslocamento ou quebra de agregados A carga máxima é denominada estabilidade Marshall e é expressa em unidade de força (no Brasil, tipicamente em kgf, ou ainda N nas normas recentes). O ensaio seguiu a norma NBR 15785:2010.

\section{RESULTADOS E DISCUSSÃO}

A Figura 1 (a) mostra os valores encontrados para a estabilidade Marshall para as amostras de mistura asfáltica com ligante convencional e ligante modificado com diversos teores de lignina. As amostras modificadas com teor $1 \%$ e $6 \%$ de lignina apresentaram redução no valor da estabilidade em $6,1 \%$ e $0,5 \%$ respectivamente. Já a amostra modificada com teor $4 \%$ apresentou um aumento no valor da estabilidade em $13 \%$, sendo, portanto, a amostra que apresentou melhor resultado.

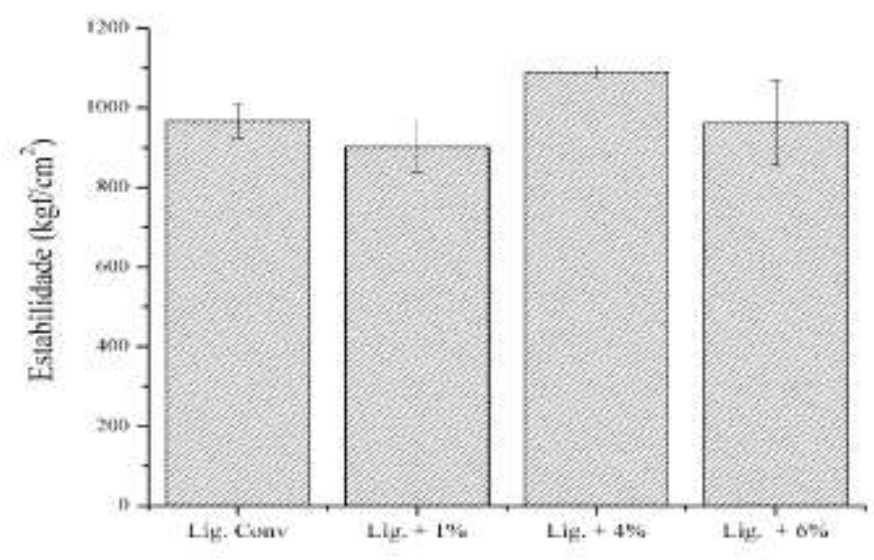

Figura 1: Estabilidade Marshall do ligante convencional e do ligante modificado com lignina.

Porém todos os valores encontrados então dentro dos requisitos de dosagem de concreto asfáltico do NBR 15785:2010, que estabelece um valor mínimo para a estabilidade de $500 \mathrm{kgf} / \mathrm{cm}^{2}$ [9]. Segundo Chen et al. [11], a adição de fibras de lignina à mistura asfáltica aumenta a estabilidade Marshall indicando sua maior resistência a trilha de roda. Este resultado pode ser atribuído a efeitos de adesão. Ainda segundo Chen et al. [11], quando a mistura asfáltica começa a apresentar trincas, a fibra de lignina serve como uma "ponte" que resiste à propagação de trincas, é o chamado "bridging cracking effect". No entanto, a mistura asfáltica é um material inconsistente, composto não uniforme e multifásico constituído de agregados e ligante asfáltico. Portanto, lignina em excesso, tal como $10 \%$, pode não se dispersar 
uniformemente, podendo coagular e formar pontos fracos dentro da mistura. Segundo Arabani e Tahami [12], a estabilidade indica a resistência da mistura asfáltica à pressão, tensão horizontal e ao cisalhamento induzido pela carga de compressão.

\section{CONCLUSÕES}

Foi produzido um concreto asfáltico com ligante asfáltico modificado com $1 \%, 4 \%$ e $6 \%$ de lignina proveniente de indústria de papel e celulose. O ligante asfáltico com $4 \%$ de lignina apresentou maior estabilidade Marshall, indicando maior resistência a trilha de roda.

\section{BIBLIOGRAFIA}

[1] SANTOS, R.E., SANTOS, I.F.S., BARROS, R.M., et al., "Generating electrical energy through urban solid waste in Brazil: An economic and energy comparative analysis", Journal of Environmental Management, v. 231, n. 1, pp. 198-206, 2019.

[2] HANNING, E., GUALBERTO, H.R., SIMÕES, K.M.A., et al., "Glass-ceramic produced with recycled glass", revista Matéria, v.24, n.4, 2019.

[3] ZACCARON, A., FRIZZO, R.G., ZANONI, E.T., et al., "Efeito da adição de resíduo de vidro em massa de cerâmica de alvenaria”, revista Matéria, v.24, n.4, 2019.

[4] SOUZA, F.B., MONTEDO, O.R.K.., GRASSI, R.L., et al., "Lightweight high strength concrete with the use of waste cenosphere as fine aggregate", revista Matéria, v.24, n.4, 2019.

[5] MEDEIROS, M.F., FRANCO, M.A.C., KLEPA, R.B., et al., "Viabilidade econômica de mantas térmicas, produzidas a partir de resíduos de asfalto, para revestimento de telhados", revista Matéria, v.24, n.4, 2019.

[6] SENA NETO, P.G., AMORIM, E.F., INGUNZA, M.P.G., et al., "Análises de dosagens de concreto asfáltico do tipo Pré Misturado a Frio" utilizando Resíduos da Construção e Demolição de obras (RCD)", revista Matéria, v.24, n.4, 2019.

[7] SILVA, E. A., FEDEL, M., DEFLORIAN, F., et al., "Post-consumer polyethylene terephthalate coating mechanically deposited on mild steels", Coatings, v. 9, pp. 28-39, 2019.

[8] BATISTA, K.B., PADILHA, R. P., CASTRO, T. O., et al., "High-temperature, low-temperature and weathering aging performance of lignin modified asphalt binders", Industrial Crops and Products, v. 111, pp. 107-116, 2018.

[9] BATISTA, K.B. "Desenvolvimento de ligantes asfálticos modificados com lignina como aditivo antienvelhecimento", Tese de Doutorado, Universidade Federal de Minas Gerais, 2017.

[10] BERNUCCI, L.B, MOTTA, L.M.G., CERATTI, J.A.P., et al., 2008. Pavimentação asfáltica: formação básica para engenheiros. Rio de Janeiro: PETROBRAS, ABEDA.

[11] CHEN, H., XU, Q., CHEN, S., ZHANG, Z., "Evaluation and design of fiber-reinforced asphalt mixtures", Materials and Design, v.30, pp. 2595-2603, 2009.

[12] ARABANI, M., TAHAMI, A. S., “Assessment of mechanical properties of rice husk ash modified asphalt mixture”, Construction and Building Materials, v. 149, pp. 350-358, 2017.

ORCID

Vanessa de Freitas Cunha Lins https://orcid.org/0000-0002-6357-9553 